was requested to see, in consultation with Mr. F. Wildbore, a middle-aged lady, residing at Stepney, who was in labour of her tenth child. She had been seized suddenly and before labour-pains had commenced, with alarming symptoms of collapse, accompanied by a very trifling oozing of blood from the vagina, but not enough to account for the extreme prostration. Before $I$ arrived the external discharge of blood had ceased; yet it was evident from the feel of the uterus that internal hanorrbage had taken place to a great extent, and that the woman was in imminent danger. Although Mr. Wildbore had judiciously administered secale cornutum, the labonr-pains were entirely suspended. The os uteri was dilated to the size of a crown piece, and there was a head presentation. To deliver in her exhausted condition would have been hazardous in the extreme. The sudden rush of blood which would probably have followed the extraction of the child, during the torpid condition of the uterus, led me to suggest the nse of stimulants, and to quietly watch their effects, before having recourse to the operation of turning. The result justified my decision. In a short time uterine pains came on, the head descended, and the labour terminated naturally.

Although the distinction drawn by Mr. Rigby, of Norwich, between those forms of hæmorrhage, occasioned by separation of the placenta from the body of the uterus, as in the above case, and such as are produced by its being placed over the mouth of the womb, is of the utmost practical value, nerertheless it appears to me that the terms "accidental" and "unavoidable," which he and the majority of modern writers have used to designate these varieties, are not only objectionable but illogical. Who will say that the hæmorrhage in the abore case was not unavoidable as well as accidental, although the placenta was not situated over the mouth of the uterus?

Homorrhage after Delivery.-The following case which I recently attended with Mr. Kisch, of Circus-place, was remarkable from having occurred at a considerable period after delivery, and from the alarming symptoms which followed the loss of only a small quantity of blood, probably amounting to not more than ten ounces.

The patient, Mrs. I- of Spitalfields, a stout but palelooking woman, twenty-six years of age, was delivered of her second child twelve days before I saw her. Mr. Kisch informed me that the hæmorrhage appeared for the first time on the ninth day, but quickly subsided. She then appeared to be going on well until the twelfth day, when the hæmorrhage returned, accompanied with extreme prostration. Mr. Kisch had succeeded in stopping the hæmorrhage before my arrival; but a most alarming state of collapse remained, associated with distressing sickness. Mr. Kisch and myself remained in close attendance the whole of the night, and it was with the greatest difficulty that life could be sustained. Frictions, sinapisms, brandy, and opium, were incessantly required during the lengthened space of eight hours, and reaction was not clearly established until the expiration of that period. The patient ultimately did well under a tonic regimen.

The points of interest in this case are the occurrence of hæmorrhage at an unusually long period after delivery, and the remarkable depression which ensued on the loss of a comparatively small quantity of blood.

External Hamorrhage before Delivery.-Last new year's eve I was summoned in haste to a Mrs. D-, a delicate woman, aged thirty, residing in the neighbourhood of Finsbury-square, and who had been seized with flooding in the seventh month of her sixth pregnancy. The loss of blood was considerable, but no very alarming symptoms had ensued ; it was, however, clear that if the hæmorrhage was not speedily checked the powers of life must soon fail. The os uteri was rigid and dilated to the size of a shilling. As all external applications and internal remedies had failed to stop the flooding, I immediately gave a strong dose of ergot, and proceeded to hasten the delivery by puncturing the membranes. Shortly afterwards pains came on; and, as soon as the parts permitted, I brought down the feet, (it was a case of breech presentation, and delivered her of a dead child. The placenta followed in quick succession, and the uterus contracted firmly. With the exception of general debility, my patient did not suffer from a single bad symptom until the end of the third week, when she was seized with headache and pain in the region of the right femoral vein, quickly followed by the usual signs of phlegmasia dolens. It is remarkable that before this attack of swelling of the leg there had been no disorder of any of the functions of the body. The lochia had subsided gradually, and all the secretions were in a healthy state. Occasional leeching, fomentations, and small doses of mercury-with-chalk combined with Dover's powder, soon reduced the swelling of the limb and restored it to its natural condition.

The accession of phlegmasia dolens so late as the twenty-first day is not a very common occurrence, although cases are on record in which it has supervened at a much later period. It is not easy to refer cases of this sort to an extension of inflammation from the uterine veins. The highly fibrinous state of the blood which exists after parturition no doubt predisposes to inflammatory affections, and it is possible that a disposition of fibrin in the vein may precede the inflammation of the blood. vessel and its surrounding textures. The occurrence of phlegmasia dolens in the lower extremities is not an invariable rule. In the early part of last year I published a case in The LanceT, in which the disease attacked the upper extremity.

Finsbury-square.

\section{ON A CASE OF OBTURATOR HERNIA.}

\section{Br ERNEST P. WILKINS, Esq., M.R.C.S.}

Mrs. M-, aged seventy, a spare and debilitated subject, was seized with pain in the abdomen and romiting during the night of April 5th, having been in good health for some time previously, with the exception of occasional constipation and dyspepsia, the bowels for days before the attack acting naturally. I was called in on the 6 th, and found her suffering from colicky pains and desire to evacuate the bowels. I prescribed aperients, enemata, \&c., without effect. The symptoms increased, and were combated by the usual treatment, but all of no avail. She died on the 17 th.

Post-mortem examination, on the 18th, disclosed an obturator hernia, the exact resemblance to a case of Mr. Fergusson's in King's College Museum, delineated in Druitt's "Vade-Mecum," p. 438, (third edition.) I have preserved the upper part of the ileum, a portion of which, about the size of the top of the forefinger, was strangulated by the ligament of the obturator foramen. I also possess the sac. The bowels above the strangulation were more or less of a claret-colour, especially near the seat of strangulation; the veins of the mesentery \&c. much congested; the ileum, below the strangulation, dwindled to the thickness of a tobacco-pipe; the colon contained a few scybala.

Newport, Isle of Wight, April, 1853.

\section{Aftiror}

OF THE PRACTICE OF

\section{MEDICINE AND SURGERY \\ IN THE \\ HOSPITALS OF LONDON.}

Nulla est alia pro certo noscendi via, nisi quam plurimas et morborum, et dissectionum historias, tum aliorum proprias, collectas habere et inter se comparare.-Morgagni. De Sed. et Cuus. Alorb., lib.14. Procemium.

\section{KING'S COLLEGE HOSPITAL.}

Puerperal Mania; Obstinate Silence and Refisal of Food; Death; Autopsy.

(Under the care of Dr. BuDD.)

THE prognosis of puerperal mania, whether the aberration occurred a long or short time after parturition, used formerly to be favourable; but obstetricians are now far more reserved as to the ultimate results of this affection. Dr. Ramsbotham, in his work on Midwifery, p. 559, alludes to the subject in the following words:- " Even the late Dr. Baillie, observant as he was of disease, and well informed upon the morbid conditions of the body in all their forms, when consulted about a case of this kind, remarked-' that the question was not whether the patient was to recover, because of that he had no doubt, but how long the disease was to last.' She died within a week after this opinion was uttered." Nor is it a wonder that patients should sink after severe attacks of puerperal mania; even were the cause of death confined to the exhaustion which naturally follows furious delirium, or to the debilitating consequences of melancholy. But among the many other modes in which this affection may lead the patient to her grave, there is one which is extremely uncontrollable - viz., the refusal of taking nourishment.

This complication is extremely difficult to treat, and though 